\title{
GENDER DIFFERENCES IN MENTAL ROTATION ABILITY IN THREE CULTURES: IRELAND, ECUADOR AND JAPAN
}

\author{
Mary FLAHERTY ${ }^{1)}$ \\ 1) University College Dublin, Ireland
}

\begin{abstract}
Literature on mental rotation tasks consistently reports that males perform better than females. The current study is an attempt to scrutinize the influence of culture and experience with spatial activities in performance on a mental rotation test. The participants were 115 Ecuadorians, 120 Irish Caucasians and 128 Japanese. Half the participants in each group were male and half were female. They completed the Group Mental Rotation Test (GMRT) and a Spatial Activities Questionnaire (SAQ). Males outperformed females on the GMRT in all three cultures. Participation in "masculine activities" from the SAQ correlated with high GMRT scores, in "feminine activities" with low GMRT scores. There was a main effect of nationality; subjects from Ireland and Japan scored higher than their counterparts in Ecuador. The implications of the nationality effect raises questions about the widely accepted stability of the gender difference in spatial ability.
\end{abstract}

Key words: mental rotation, gender differences, cross-cultural study

The literature on gender differences in spatial abilities in adults is abundant (Maccoby \& Jacklin, 1974). While no clear definition of spatial ability exists as yet (Caplan \& Caplan, 1998), it is generally accepted that spatial ability comprises several skills, including mental rotation, spatial perception and spatial visualization (Flaherty, 1997; MacIntyre, 1997). This paper focuses on mental rotation which is the ability to imagine how objects appear when they are rotated. Superior performance among males on mental rotation tests has been noted consistently by several reviewers (Halpern, 1992; Matlin, 1987; Voyer, Voyer, \& Bryden, 1995). Indeed meta-analytic findings indicate the gender difference as evidenced in the Group Mental Rotation Test (Vandenberg \& Kuse, 1978) to be the strongest of all spatial tests, with an effect size (d) of 0.73 (Linn \& Peterson, 1986).

The superior performance among males in tests of spatial ability has been the subject of much debate (see Linn \& Peterson, 1985; Newcombe, 1982). One issue has been the degree to which this advantage reflects biological versus environmental and socialization differences (Collaer \& Hines, 1995; McGee, 1982; Thomas, 1983) between males and females.

The theory that hormones influence the development of the gender difference in

This study was supported by a President's Award from University College Dublin, and a Visiting Research Grant from Kwansei Gakuin University, Japan. I am grateful to the students at La Salle Colegio Conocito, Pontificia Universidad Catolica del Ecuador, Kwansei Gakuin University and University College Dublin for their kind participation.

Correspondence concerning this article should be addressed to Mary Flaherty, Department of Psychology, University College Dublin, Dublin 4, Ireland (e-mail: mary.flaherty@ucd.ie). 
spatial ability has received some support (McGee, 1979). Waber (1977) hypothesized that timing of puberty effects might explain sex-related differences in spatial ability. However, Newcombe, Dubas, and Baenninger (1989) found no significant correlation between age at menarche and spatial ability in a group of undergraduate women. Reasons such as differences in cerebral organization (Casey, 1996; Casey \& Brabeck, 1989) and a recessive $\times$ chromosome linked trait (Stafford, 1961; Thomas \& Jamison, 1981) have been put forward as explanations for the male advantage. Sherman (1978) extensively reviewed the literature on the genetic link hypothesis of spatial abilities and concluded that the overwhelming number of studies failed to confirm the hypothesis, and the few studies that supported the hypothesis lacked scientific rigor.

Socialization models explain the gender difference in terms of environmental influences (Gauvain, 1993; Sherman, 1967; Sprafkin, Serbin, Denier, \& Connor, 1983; Tracy, 1987). They are based on the assumption that in our culture, boys are more strongly encouraged than girls to participate in activities that promote the development of spatial skills (e.g., block play, carpentry, model building, tinkering with and driving cars, computer games, math and science courses). Indeed, Lord and Garrison (1998) found that women active in intercollegiate athletics score significantly higher than their male counterparts in tests of spatial ability. This result may be linked to specific hormones (McGee, 1979), but could equally be due to experience in a sport requiring much practice in a spatial skill. Gender differences on an applied mental rotation task (Kass, Ahlers, \& Dugger, 1998) have been shown to be reduced through programmed experience (i.e., training). Thus it becomes theoretically more likely that the performance differences derive primarily from socialization and, even more so, that they do not reflect fundamental differences in competencies between males and females. It may be the case that the skills that are tested in spatial ability batteries are part of the activities that boys are more likely to have experience with. Because the magnitude of sex-related differences in spatial ability appears to increase over time (Kinsbourne, 1980), it is plausible that these differences are partially or entirely produced by sex-role stereotyping.

That differences on spatial tasks have an experiential component is further supported by the fact that much of the evidence reporting the superiority of men over women on visual tests (McGee, 1982) concerns primarily individuals from Western cultures (see Caplan, MacPherson, \& Tobin, 1985 for a critical evaluation). There are few data regarding sex differences among individuals from non-Western cultures and what data there are do not always replicate the Western pattern of results (Wilson, DeFries, McClearn, Vandenberg, Johnson, \& Rashad, 1975). Mann, Sasanuma, Sakuma, and Masaki (1990) found no significant sex difference on the Spatial Orientation WISC-R maze test in a Japanese sample. In an experimental study of nomadic, nonmissionized preliterate Auca Indians of the Ecuadorian Amazon basin (Pontius, 1991), in which various spatial tests were employed, women outperformed their male counterparts.

The present study examined the performance of women and men from three different countries (Ireland, Japan and Ecuador), on a mental rotation test, taking their experience with spatial activities into account. The Group Mental Rotation Test (GMRT) (Vandenberg \& Kuse, 1978), which comprises figures from Shepard and Metzler's classic 
study on mental rotation (Shepard \& Metzler, 1971), was used as a measure of mental rotation. Participation in space related activities was measured with the Spatial Activities Questionnaire (see details below). It was hypothesized that males would outscore females on the GMRT, supporting this consistent finding in the literature. If this superiority is due primarily to a genetic factor, then the males' advantage should exist irrespective of culture and spatial activities experience. However, if experience influences spatial ability, then participation in those who partake in more "masculine activities" than "feminine activities" should score high on the GMRT, irrespective of their gender. If socialization and culture play a role in spatial performance, differences in performance of participants from the three countries might reflect such influences.

\section{METHOD}

\section{Participants:}

115 Ecuadorians (of mixed Spanish and Indian background), 120 Irish Caucasian, and 128 Japanese people participated in the experiment . Among the Ecuadorians, 57 were male (Mean age $=17.47, S D=2.40$ ) and 58 were female (Mean age $=18.10, S D=3.01$ ); among the Irish, 60 were male (Mean age $=20.43, S D=1.75$ ) and 60 were female (Mean age $=18.76, S D=2.51$ ); and among the Japanese, 64 were male (Mean age $=19.88$, $S D=2.49$ ) and 64 female (Mean age $=20.59, S D=1.12$ ). All were college students.

To reduce the possibility that some individuals might have atypical brain organization (Kraft \& Nickel, 1995), only right handed people were selected. A total of 28 potential respondents were dismissed from the study as a result. A further 70 were rejected for not completing the questionnaires. These 98 individuals were removed prior to analysis and are not included among the participants outlined above.

\section{Materials:}

Two types of material, the GMRT and a Spatial Activities Questionnaire were employed and will be explained in turn.

The GMRT (Vandenberg \& Kuse, 1978) is a 40-item, objective test of spatial visualization ability. It requires participants to make judgments concerning the orientation of various three-dimensional objects composed of blocks placed together end-to-end forming three right angles. Each item contains a target figure and four alternatives, two of which are correct and two of which are incorrect (mirror-image) "distracters". Performers must decide which two of the four alternatives are the same as, although in a different orientation from, the target figure. In large samples in which this test has been used (see McGee, 1979, 1982 for details) there have been clear indications of substantial internal consistency and test-retest reliability. It has shown a high correlation with a number of other tests of visual and spatial ability (Kuse, 1977; Vandenberg \& Kuse, 1978).

The modified version of the Spatial Activities Questionnaire (SAQ) (Newcombe, Bandura, \& Taylor, 1983; Signorella, Krupa, Jamison, \& Lyons, 1986; Sherman, 1967) was used.This questionnaire consists of a list of 24 activities, 8 of which are considered "masculine" and relevant to spatial ability, 8 "feminine" and 8 "neutral" and less pertinent to spatial skills. The "masculine activities" are carpentry, making/fixing radios, building train/car sets, electrical circuitry, shooting, football, car repair and baseball; the "feminine activities", ballet, embroidery, knitting, decorating, quilting, skating, crocheting, gymnastics; the "neutral activities", bowling, tennis, drawing, volleyball, diving, ping-pong, painting and racquetball. The SAQ was analyzed following Signorella et al. (1986) and Newcombe et al. (1983).

The materials were back-translated from English to Spanish and Japanese following the guidelines set out by Brislin (1970), recommending that translators familiar with the content of the material should be used. Two Spanish nationals and two Japanese nationals, a professional translator and a language teacher in each case, performed translations. Two mother tongue English speakers compared the originals and the back translated versions. Both agreed on the semantic equivalence of both versions. 
Table 1. Performance Scores on GMRT of Males and Females from Ecuador, Ireland and Japan

\begin{tabular}{|c|c|c|c|c|c|c|}
\hline & \multicolumn{6}{|c|}{ Participants $(N=363)$} \\
\hline & \multicolumn{2}{|c|}{$\operatorname{Men}(n=181)$} & \multicolumn{2}{|c|}{ Women $(n=182)$} & \multicolumn{2}{|c|}{ Total } \\
\hline & $M$ & $S D$ & $M$ & $S D$ & $M$ & $S D$ \\
\hline \multicolumn{7}{|l|}{ Countries } \\
\hline Ecuador $(n=115)$ & 15.15 & 7.80 & 8.29 & 5.34 & 11.69 & 7.49 \\
\hline Ireland $(n=120)$ & 23.00 & 9.51 & 11.85 & 6.62 & 17.42 & 9.89 \\
\hline Japan $\quad(n=128)$ & 20.48 & 10.47 & 14.03 & 7.07 & 17.25 & 9.47 \\
\hline Total $S \mathrm{~s}$ & 19.64 & 9.87 & 11.48 & 6.80 & & \\
\hline
\end{tabular}

Procedure:

Participants completed the GMRT and SAQ in their native countries in their native languages. Each of sections 1 and 2 of GMRT were completed in 3 minutes. Participants took as much time as they needed to complete the SAQ, which averaged about 3 minutes. The GMRT and SAQ were administered in a random order. Participants were tested in groups of 10-15.

\section{RESULTS}

Males scored higher than females on the GMRT $(t(360)=9.16, p<.0001)$. This trend was found in each country (Ecuador: $t(113)=5.49, p<.0001$; Ireland: $t(118)=7.45$, $p<.0001$; Japan: $t(126)=4.084, p<.0001$ ) (see Table 1).

The more "masculine activities" one participated in, the higher the GMRT score $(r=.215, p<.01)$. This trend was observed in each country (Ecuador: $r=.312, p<.01$; Ireland: $r=.409, p<.01$; Japan: $r=.321, p<.01)$. In opposition to this trend, there was a negative correlation between the number of feminine activities which subjects performed and the GMRT score $(r=-.225, p<.01)$; this trend reached statistical significance only in Ireland (Ireland: $r=-.271, p<.01$; Ecuador: $r=-.134, n s$; Japan: $r=-.107, n s$ ). There was no correlation between the neutral activities and the GMRT score $(r=-.024, n s)$. Males partook in more masculine activities than females $\left(\chi^{2}=51.11, p<.0001\right)$ and females in more feminine activities $\left(\chi^{2}=31.95, p<.0001\right)$ This trend was evident in all three cultures (see Table 2).

An ANOVA revealed that nationality was a significant factor influencing the GMRT score $(F(2,360)=15.30, p<.0001)$. A post hoc Tukey test unveiled that both the Irish and Japanese participants performed significantly better than their Ecuadorian counterparts $(t=-4.85, p<.001$ and $t=-4.78, p<.001$ respectively) (see Table 1$)$. 
Table 2. Mean Number of "Masculine", "Feminine" and "Neutral Activities" Participated in by Males and Females in Ecuador, Ireland and Japan, and Total Subject Group

\begin{tabular}{|c|c|c|c|c|c|c|}
\hline & \multicolumn{2}{|c|}{ Masculine Activities } & \multicolumn{2}{|c|}{ Feminine Activities } & \multicolumn{2}{|c|}{ Neutral Activities } \\
\hline & $M$ & $S D$ & $M$ & $S D$ & $M$ & $S D$ \\
\hline \multicolumn{7}{|l|}{ Ecuador } \\
\hline Males & 3.03 & 2.06 & 1.07 & 1.16 & 1.89 & 1.35 \\
\hline Females & 1.00 & 1.32 & 1.91 & 1.51 & 2.03 & 1.15 \\
\hline \multicolumn{7}{|l|}{ Ireland } \\
\hline Males & 2.05 & 1.40 & 0.40 & 0.76 & 1.88 & 0.88 \\
\hline Females & 0.61 & 0.84 & 1.45 & 1.26 & 2.88 & 1.82 \\
\hline \multicolumn{7}{|l|}{ Japan } \\
\hline Males & 1.18 & 1.16 & 0.50 & 0.79 & 1.81 & 1.45 \\
\hline Females & 0.34 & 0.51 & 1.01 & 1.26 & 2.29 & 1.56 \\
\hline \multicolumn{7}{|c|}{ Total $S$ s group } \\
\hline Males & 2.05 & 1.74 & 0.64 & 0.95 & 1.86 & 1.57 \\
\hline Females & 0.64 & 0.97 & 1.44 & 1.39 & 2.40 & 1.54 \\
\hline
\end{tabular}

\section{DISCUSSION}

Males outscored the females on GMRT in all three cultures, reiterating the superior performance of males reported in previous studies (Halpern, 1992; Matlin, 1987; Voyer et al.,1995). Males also engaged in more "masculine activities" than their female counterparts, which may have enhanced their spatial awareness. So we arrive at the age old question : Did they engage in more spatially demanding tasks because of their superior spatial intelligence or did their preferred hobbies enhance their spatial awareness?

A resolution to the relative influence of biology and experience on mental rotation performance may be met in the finding that participants from one culture, Ecuador, performed consistently lower than those in Ireland and Japan. This main effect of nationality is of major interest. Participants were carefully matched in terms of age, education and social background. Perhaps Japanese and Irish cultures encourage more spatially demanding tasks, such as computer games, than that in Ecuador. The capacity for reorganization of the central nervous system in response to environmental stimuli demonstrates the critical importance of reassessing this debate in terms of enriched experience (Back-y-Rita, 1980). For example, the use of a visuo-spatial language, sign, appears to enhance spatial ability. Deaf people who sign outscore their hearing counterparts on visual memory tests (Bellugi, O'Grady, Lillo-Martin, O'Grady Hynes, Van Hoek, \& Corina, 1990). It is plausible that socialization and experience are the prime predictors of spatial performance. 
However, the picture may not be so simple. When we study the results in more detail, we note that Japanese females and males in Ecuador were almost identical in their GMRT scores, but males in Ecuador showed ten times more masculine activities than the Japanese females. The same trend was found between the Japanese females and females in Ecuador. Females in Ecuador exhibited three times more masculine activities than Japanese females, yet Japanese females were better than females in Ecuador in their GMRT performance. If it is simply "socialization" and experience with masculine activities that are responsible for the observed GMRT differences, then males in Ecuador, who engage in ten times more masculine activities than Japanese females, should have been better than the latter in their GMRT performance. Likewise, females in Ecuador, who engaged in three times more masculine activities than Japanese females, should have outperformed the latter in the GMRT. The data did not support this trend. This raises the question of how reliable such scores as SQT are in terms of accessing a subjects' spatial ability. Perhaps, other external factors, such as test-taking skills and motivation might have influenced the subjects' GMRT performance more than the amount of "masculine activities" per se. This then is a classic "Catch-22" scenario. Those who are used to doing tests outperform those who are not, and to test and compare the latter with the former simply shows that those who are used to doing tests outperform those who are not!

The present study is limited in its assessment of two factors, the influence of motivation and ethnic differences. Japan and Ireland are more test conscious cultures and therefore participants from those societies may have been more internally motivated to complete the test with greater accuracy than the participants from Ecuador. There was no internal motivating aspect built into the design. Ethnic differences were not examined. While all Irish participants were Caucasian, and Japanese were ethnic Japanese, Ecuadorian participants were of mixed Spanish and Indian blood. It would perhaps be of interest to examine only those of Indian origin. Racial differences have been noted in the literature on spatial ability. For example, Baughman and Dahlstrom (1968) found a male superiority in a group of 437 White children in the spatial relations subtest of Thurstone's Primary Mental Abilities Test (Thurstone, 1963). In the same study, there were no sex differences for the 642 Black children tested.

The findings of this study confirm a gender difference in mental rotation ability. However, irrespective of gender and experience, a cultural difference is also present, highlighting the importance of socialization factors, and indeed test-taking experience. Considering the importance of spatial abilities in "real life" tasks (Carter \& Woldstad, 1985), further research is warranted on strategies for improving these abilities. Whether the data can be interpreted to mean that the gender differences that currently apparently exist in spatial abilities will one day follow the same course as those previously characterizing verbal and mathematical skills, and so eventually be eroded by changing cultural and socialization practices (Feingold, 1988; Hyde, Fennema, \& Lamon, 1990; Hyde \& Linn, 1988), remains to be determined. 


\section{REFERENCES}

Back-y-Rita, P. 1980. (Ed.). Recovery of function: Theoretical considerations for brain injury rehabilitation. Baltimore: University York Press.

Baughman, E. E., \& Dahlstrom, W. G. 1968. Negro and white children: A psychological study in the rural south. New York: Academic Press.

Bellugi, U., O’Grady, L., Lillo-Martin, D., O’Grady Hynes, M., Van Hoek, K., \& Corina, D. 1990. Enhancement of Spatial Cognition in Deaf Children. In V. Volterra \& C. J. Erting (Eds.), From gesture to language in hearing and deaf children. (pp. 278-298). Berlin: Springer Verlag.

Brislin, R. W. 1970. Back-translation for cross-cultural research. Journal of Cross-Cultural Psychology, 1, 185-216.

Caplan, P. J., \& Caplan, J. B. 1998. Thinking citically aout rsearch on sx and gender. New York: AddisonWesley.

Caplan, P. J., MacPherson, G. M., \& Tobin, P. 1985. Do sex-related differences in spatial abilities exist? American Psychologist, 40, 786-799.

Carter, R., \& Woldstad, J. 1985. Repeated measurements of spatial ability with the Manikin test. Human Factors, 27, 209-219.

Casey, M. B. 1996. Understanding individual differences in spatial ability within females: A nature/nurture interactionist framework. Developmental Review, 16, 241-260.

Casey, M. B., \& Brabeck, M. M. 1989. Women who excel on a spatial task: Proposed genetic and environmental factors. Brain and Cognition, 12, 73-84.

Collaer, M. L., \& Hines, M. 1995. Human behavioral sex differences: A role for gonadal hormones during early development. Psychological Bulletin, 118, 55-107.

Feingold, A. 1988. Cognitive gender differences are disappearing. American Psychologist, 43, 95-103.

Flaherty, M. 1997. The validity of tests of visuo-spatial skills in cross-cultural studies. The Irish Journal of Psychology, 18, 404-412.

Gauvain, M. 1993. Spatial thinking and its development in sociocultural context. Annals of Child Development, 9, 67-102.

Halpern, D. F. 1992. Sex differences in cognitive abilities (2nd ed.). Hillsdale, NJ: Lawrence Erlbaum.

Hyde, J. S., Fennema, E., \& Lamon, S. J. 1990. Gender differences in visual-spatial ability: The role of performance factors. Memory and Cognition, 18, 546-550.

Hyde, J. S., \& Linn, M. C. 1988. Gender differences in verbal ability: A meta-analysis. Psychological Bulletin, 104, 53-69.

Kass, S. J., Ahlers, R. H., \& Dugger, M. 1998. Eliminating gender differences through practice in an applied visual spatial task. Human Performance, 11, 337-349.

Kinsbourne, M. 1980. If sex differences in brain lateralization exist, they have not been discovered. The Behavioral and Brain Sciences, 3, 241-242.

Kuse, A. R. 1977. Familial resemblances for cognitive abilities estimated from two test batteries in Hawaii. Unpublished doctoral dissertation. University of Colorado, $\mathrm{CO}$.

Linn, M. C., \& Peterson, A. 1985. Emergence and characterization of gender differences in spatial ability: A meta analysis. Child Development, 56, 1479-1498.

Linn, M. C., \& Peterson, A. C. 1986. A meta-analysis of gender differences in spatial ability: Implications for mathematics and science achievement. In J. S. Hyde \& M. C. Linn (Eds.), The psychology of gender: Advances through meta-analysis (pp. 67-101). Baltimore, MD: Johns Hopkins University Press.

Lord, T. R., \& Garrison, J. 1998. Comparing spatial abilities of collegiate athletes in different sports. Perceptual and Motor Skills, 86, 1016-1018.

Maccoby, E. E., \& Jacklin, C. N. 1974. The psychology of sex differences. Stanford, CA: Stanford University Press.

MacIntyre, T. 1997. Gender differences in cognition: A minefield of research issues. The Irish Journal of Psychology, 18, 386-396.

Mann, V. A., Sasanuma, S., Sakuma, N., \& Masaki, S. 1990. Sex differences in cognitive abilities: A crosscultural perspective. Neuropsychologia, 28, 1063-1077.

Matlin, M. W. 1987. The psychology of women. New York: Holt, Rinehart \& Winston. 
McGee, M. G. 1979. Human spatial abilities: Psychometric studies and environmental, genetic, hormonal, and neurological influences. Psychological Bulletin, 86, 889-918.

McGee, M.G. 1982. Spatial abilities: the influence of genetic factors. In M. Potegal (Ed.), Spatial abilities development and physiological foundations (pp. 199-222). New York: Academic Press.

Newcombe, N. 1982. Sex-related differences in spatial ability: Problems and gaps in current approaches. In M. Potegal (Ed.), Spatial abilities: Development and physiological foundations (pp. 223-250). New York: Academic Press.

Newcombe, N., Bandura, M., \& Taylor, D. 1983. Sex differences in spatial ability and spatial activities. Sex Roles, 9, 377-386.

Newcombe, N., Dubas, J. S., \& Baenninger, M. 1989. Associations of timing of puberty with spatial ability: Do they persist into adulthood? Child Development, 60, 246-254.

Pontius, A. A. 1991. Cross-evolutionary spatial representation in stone-age ecology. Behavioral and Brain Sciences, 14, 522-523.

Shepard, R. N., \& Metzler, J. 1971. Mental rotation of three-dimensional object. Science, 171, 701-703.

Sherman, J. A. 1967. Problem of sex differences in space perception and aspects of intellectual functioning. Psychological Review, 74, 290-299.

Sherman, J. A. 1978. Sex-related cognitive differences: An essay on theory and evidences. Springfield, IL: Charles C. Thomas.

Signorella, M. L., Krupa, M. H., Jamison, W., \& Lyons, N. 1986. A short version of a spatial activities questionnaire. Sex Roles, 14, 475-479.

Sprafkin, C., Serbin, L. A., Denier, C., \& Connor, J. M. 1983. Sex-differentiated play: Cognitive consequences and early interventions. In M. B. Liss (Ed.), Social and cognitive skills: Sex roles and children's play (pp. 167-192). New York: Academic Press.

Stafford, R. E. 1961. Sex differences in spatial visualization as evidence of sex-linked inheritance. Perceptual and Motor Skills, 13, 428.

Thomas, H. 1983. Familial correlational analyses, sex differences, and the X-linked gene hypothesis. Psychological Bulletin, 93, 427-440.

Thomas, H., \& Jamison, W. 1981. A test of the X-linked genetic hypothesis for sex differences on Piaget's water-level task. Developmental Review, 1, 274-283.

Thurstone, L. L. 1963. Primary mental abilities test. Chicago: Science Research Associates.

Tracy, D. M. 1987. Toys, spatial ability, and science and mathematics achievement: Are they related? Sex Roles, 17, 115-138.

Vandenberg, S. G., \& Kuse, A. R. 1978. Mental Rotations, a group test of three-dimensional spatial visualization. Perceptual and Motor Skills, 47, 599-604.

Voyer, D., Voyer, S., \& Bryden, M. P. 1995. Magnitude of sex differences in spatial abilities: A metaanalysis and consideration of critical variables. Psychological Bulletin, 117, 250-270.

Waber, D. P. 1977. Sex differences in mental abilities, hemispheric specialization and rate of physical growth at adolescence. Developmental Psychology, 13, 29-38.

Wilson, J. R., DeFries, J. C., McClearn, G. E., Vandenberg, S. G., Johnson, R. C., \& Rashad, M. N. 1975. Cognitive abilities: Use of family data as a control to assess sex and age differences in two ethnic groups. International Journal of Aging and Human Development, 6, 261-276.

(Manuscript received June 29, 2004; Revision accepted December 28, 2004) 